\title{
Reduced Rating Active Phase Converter for Three Phase Induction Generator based Single Phase Grid-Tied Systems
}

\author{
Anil K Adapa \\ Department of Electrical Engineering \\ Indian Institute of Science \\ Bengaluru, India \\ anilkumaradapa@gmail.com
}

\author{
Vinod John \\ Department of Electrical Engineering \\ Indian Institute of Science \\ Bengaluru, India \\ vjohn@ee.iisc.ac.in
}

\begin{abstract}
The distribution systems and microgrids in remote and rural areas are often of single-phase in nature due to economic viability. However, three-phase induction generators (IG) is a popular machine even in such applications due to the large utility and its competitive price features. This paper proposes a control approach for injecting power to a single-phase grid from an active phase converter (APC) assisted three-phase IG. The presented approach ensures balanced operation of the IG even with variable generation. A method is proposed that reduces the loading on the APC and improves operating power factor at the single-phase grid. Closed form expression of the grid current for a given operating point of the IG is derived. Simulation and experimental results are provided to validate the theoretical framework and APC control approach. The experimental results with a $3 \mathrm{~kW}$ IG substantiate the proposed APC control approach injecting $2.6 \mathrm{~kW}$ real power into the single-phase grid at near unity power factor.
\end{abstract}

Index Terms-Active phase-converter, induction generator, PWM converter, digital control, distributed generation.

\section{INTRODUCTION}

In remote regions and rural areas three-phase supply may not be available, some places need to rely upon the microgrids due to inaccessible geographical conditions [1], [2]. Most of the loads in aforementioned situations are single-phase in nature [3]. Supplying power to such loads with a lowcost generation or cogeneration systems, which access nonconventional energy sources like wind and hydro power is preferred [4]-[6]. Squirrel cage induction machine (SCIM) based wind, micro hydel and distributed generation schemes are attractive solutions due to the advantages such as availability, low cost and reduced maintenance needs [1], [4].

Operating a three-phase induction generator (IG) with a single-phase load is an extreme case of unbalance, results in pulsating developed torque which is detrimental to the drive train [7]. IG needs to be de-rated to operate within the allowable thermal limits due to the undesirable rotor current harmonics [1]. Steinmetz connection using single excitation capacitor is a simple method to reduce unbalanced voltages

This work was supported by CPRI, Ministry of Power, Government of India, under the project Power conversion, control, and protection technologies for microgrid.

978-1-5386-9316-2/18/\$31.00 2018 IEEE and currents in the IG system [8]. Two excitation capacitors based methods [9], and transformer based current injection technique in conjunction with excitation capacitors [4] offer reasonable phase balance and improve power factor at the grid. However, these passive and self-excitation schemes are suitable only where the load voltage and frequency regulations are not stringent.

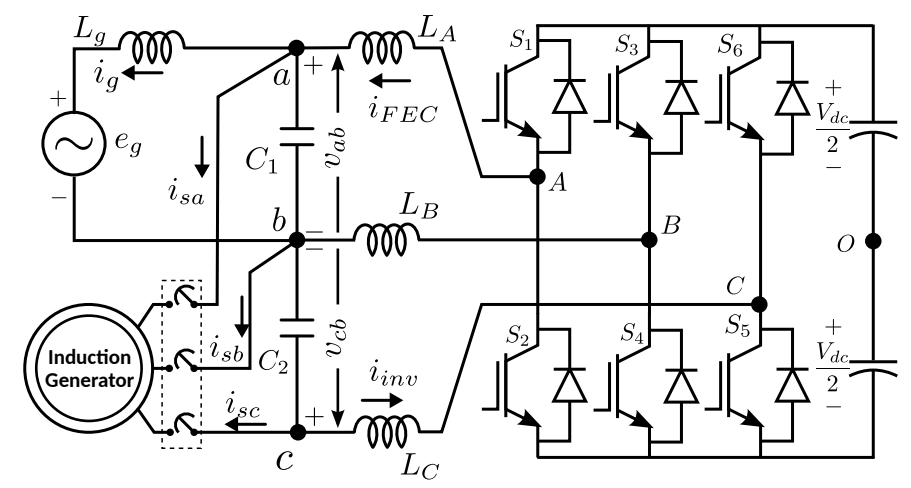

Fig. 1. APC based IG circuit topology for single-phase grids.

A power converter assisted shunt compensator based excitation control and power balancer with a battery connected converter is reported in [10]. An Active Phase Converter (APC) aids in balanced loading of a three-phase IG powering single-phase or unbalanced load. This paper proposes a reduced switch APC control to inject power from a threephase IG to a single-phase grid. The proposed method results in balanced loading of the IG by creating a virtual third phase with a reduced switch power converter topology. There are two possible cases for the line voltages of the converter where (i) the line voltage $v_{c b}$ leads $v_{a b}$ and (ii) the line voltage $v_{c b}$ lags $v_{a b}$. It is shown that for the induction generator, use of $v_{c b}$ leading $v_{a b}$ results in a significant reduction in the converter currents and also improvement in the grid power factor. On the other hand, the converse, voltage sequence control in which $v_{c b}$ lagging $v_{a b}$ is benefecial for inductive loads [11].

This paper gives the analytical expressions of the grid and active front end converter currents and the control approach that minimizes loading on the APC under generation mode. 


\section{Active Phase Converter Circuit}

Fig. 1 shows an active phase converter (APC) topology with bi-directional power processing capability [8]. Two legs $\mathrm{A}$ and $\mathrm{B}$ establish the required $\mathrm{dc}$ bus voltage by operating as a single-phase front end converter with an LCL filter. $v_{a b}$ is the grid voltage at the point of common coupling (PCC). Desired fundamental voltage $v_{c b}$ at the output of LC filter is achieved by suitably controlling the converter legs $\mathrm{B}$ and $\mathrm{C}$ as a single-phase inverter. APC realizes balanced three phase supply at the load terminals by controlling the magnitude of the $v_{c b}$ to be the same as that of the $v_{a b}$ with a phase shift of $60^{\circ}$ as shown in Fig. 3. This is possible if $v_{c b}$ lags or leads $v_{a b}$ by $60^{\circ}$, as in both cases balanced three-phase supply is achieved. The two methods have different phase sequences.

In order to operate the APC in conjunction with an IG, a phasor based approach is utilized for generation of appropriate references for the controllers. The proposed technique has the added benefit of reduced device current stress and improved power factor at the grid. In this work, it is shown that $60^{\circ}$ lead control of the APC is most suitable for IG operation in terms of the peak current requirement of the FEC and the grid power factor. This is unlike the case of a typical motor load where the lagging control of $v_{c b}$ is considered desirable [8], [11].

\section{A. Control Approach}

The single-phase FEC of APC employes a proportional and resonant controller based inner current loop; a proportional and integral (PI) controller based outer voltage loop [12]. The FEC with LCL draws required real power to maintain dc link voltage at the desired level also mitigates the ripple current injected into the grid. In the APC, LC filter at converter legs $\mathrm{B}$ and $\mathrm{C}$, maintains the power quality at the IG terminals by filtering the harmonic content of the PWM line voltage. The active damping of LC filter based control to generate required $v_{c b}$ at the IG terminals is given in Fig. 2. The control is a cascaded two loop structure, where outer voltage loop controller generates the current reference to the inner loop to track the sensed $v_{c b}$ with the reference signal $v_{c b}^{*}$. The inner current control loop provides the essential damping to the LC resonance oscillations. A controller design method of virtual resistor based active damping for inverter with LC filter presented in [13] is incorporated. The decoupled control of FEC and the inverter APC with a shared converter Leg-B is achieved using similar control method presented in [8]. Threephase induction generator experiences a balanced three-phase terminal voltage, by controlling the devices of converter Leg$\mathrm{B}$ and Leg-C appropriately. The filtered voltage $v_{c b}$ can lead or lag the voltage at point of common coupling $v_{a b}$ by $60^{0}$ to obtain balanced three phase supply. Feed forward signals for the APC legs A and B and the reference signal for the inverter are generated using the method suggested in [8].

\section{ANALYSIS}

The IG draws required reactive power for excitation from the grid and APC. The induction generator delivers a part of real power directly to the grid while the remaining power is delivered to the inverter which in-turn injected to the grid by the FEC. The analysis identifies an appropriate control method in terms of lead or lag control that reduces the loading on the FEC and the reactive power demand from the grid.

\section{A. Current Phasor}

In this section closed-form expressions for the grid and FEC currents of the APC with the proposed control are derived. Reactive power associated with the filter components of the converter is not taken into account for the subsequent analysis. Let the real and reactive power drawn by the IG be assumed to be $P+j Q$. The value of $\mathrm{P}$ is negative indicating real power $(\mathrm{kW})$ injected to the grid and positive value of $Q$ indicate reactive power (kVAR) consumed by the IG. Magnitude of the grid and inverter voltages is $V$, which is the line to line voltage seen by the IG. The phase angle of the line currents of the IG with respect to the respective phase is given by,

$$
\theta_{s a}=\tan ^{-1}\left(\frac{Q}{P}\right)=180^{\circ}-\tan ^{-1}\left(\frac{|Q|}{|P|}\right)=180^{\circ}-\theta_{r}
$$

where, $P$ is negative and $Q$ is positive for induction generators.

The generation mode of operation of the IG can be observed by the IG phase voltages $V_{a n}, V_{a n}$ and $V_{a n}$, and the phase currents $I_{s a}, I_{s b}$ and $I_{s c}$ in Fig. 4.

\section{B. Control with $v_{c b}$ that lags $v_{a b}$}

IG currents corresponding to the line and phase voltages of the case $v_{c b}$ lags $v_{a b}$ as shown in the Fig. 4(a) are,

$$
\begin{gathered}
\mathbf{V}_{\mathbf{a b}}=V \angle 0^{\circ}, \mathbf{V}_{\mathbf{b c}}=V \angle 120^{\circ}, \mathbf{V}_{\mathbf{c a}}=V \angle-120^{\circ} \\
\mathbf{V}_{\mathbf{a n}}=\frac{V \angle 30^{\circ}}{\sqrt{3}}, \mathbf{V}_{\mathbf{b n}}=\frac{V \angle 150^{\circ}}{\sqrt{3}}, \mathbf{V}_{\mathbf{c n}}=\frac{V \angle-90^{\circ}}{\sqrt{3}} \\
\mathbf{I}_{\mathbf{s a}}=I \angle-150^{\circ}+\theta_{r}, \mathbf{I}_{\mathbf{s b}}=I \angle-30^{\circ}+\theta_{r}, \mathbf{I}_{\mathbf{s c}}=I \angle 90^{\circ}+\theta_{r}
\end{gathered}
$$

Power supplied by the inverter,

$$
\begin{aligned}
P_{i n v}+j Q_{i n v} & =\mathbf{V}_{\mathbf{c b}} \mathbf{I}_{\mathbf{s c}}^{*} \\
& =V I\left\{-\cos \left(30^{\circ}-\theta_{r}\right)-j \sin \left(30^{\circ}-\theta_{r}\right)\right\}
\end{aligned}
$$

Real power drawn by the FEC is same as the real power delivered by the inverter. FEC current is given by,

$$
\mathbf{V}_{\mathbf{a b}} \mathbf{I}_{\mathbf{F E C}}=-V I \cos \left(30^{\circ}-\theta_{r}\right) \Rightarrow \mathbf{I}_{\mathbf{F E C}}=-I \cos \left(30^{\circ}-\theta_{r}\right)
$$

Grid current,

$$
\begin{aligned}
& \mathbf{I}_{\mathbf{g}}=\mathbf{I}_{\mathbf{S a}}+\mathbf{I}_{\mathbf{F E C}}=I \angle-150^{\circ}+\theta_{r}-I \cos \left(30^{\circ}-\theta_{r}\right) \\
& \Rightarrow \mathbf{I}_{\mathbf{g}}=-\sqrt{3} I \cos \left(\theta_{r}\right)-j I \sin \left(30^{\circ}+\theta_{r}\right)
\end{aligned}
$$

Power drawn from the single-phase grid,

$$
P+j Q=\mathbf{V}_{\mathbf{a b}} \mathbf{I}_{\mathbf{g}}^{*}=V I\left\{-\sqrt{3} \cos \left(\theta_{r}\right)+j \sin \left(30^{\circ}+\theta_{r}\right)\right\}
$$




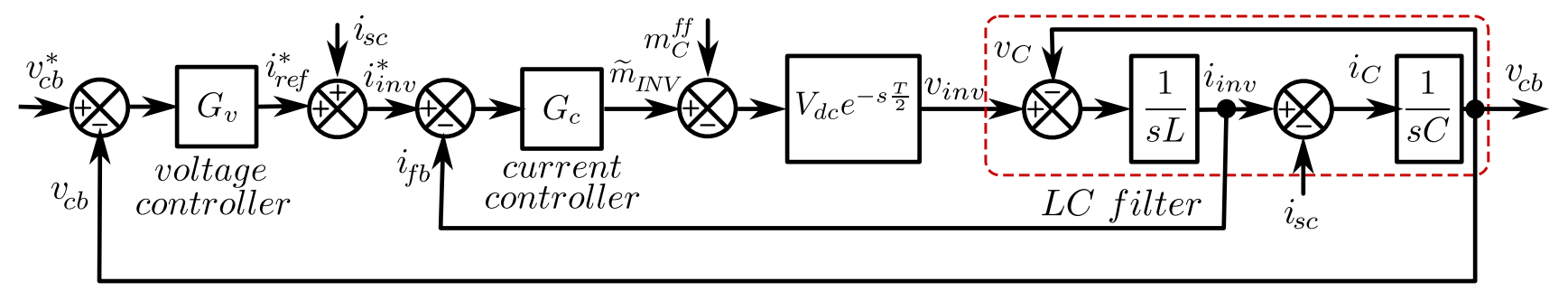

Fig. 2. Block diagram of the inverter control used to generate balanced three-phase voltage.

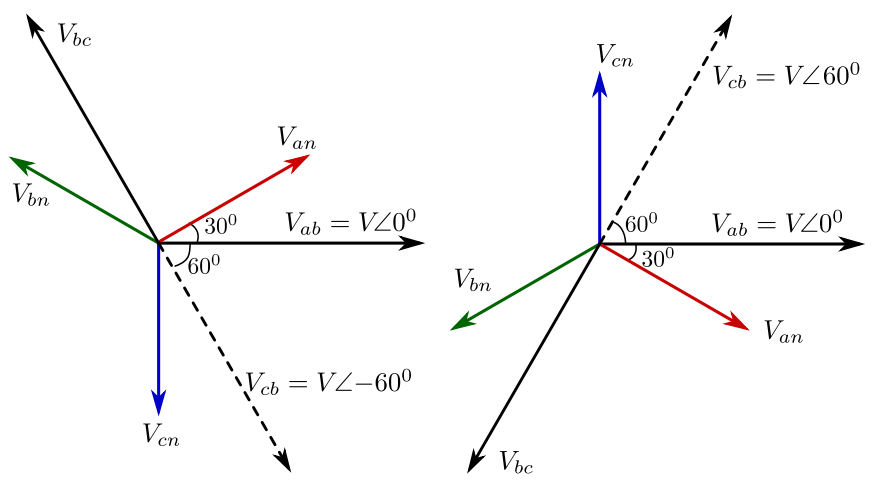

Fig. 3. Phasor diagram of APC lag and lead control to generate three phase supply.

C. Control with $v_{c b}$ that leads $v_{a b}$

Similar to the previous section, expressions for the grid and FEC current are, For the case, $v_{c b}$ lags $v_{a b}$, the line and phase voltages are,

$\mathbf{V}_{\mathbf{a b}}=V \angle 0^{\circ}, \quad \mathbf{V}_{\mathbf{b c}}=V \angle-120^{\circ}, \quad \mathbf{V}_{\mathbf{c a}}=V \angle 120^{\circ} ;$

$\mathbf{V}_{\text {an }}=\frac{V}{\sqrt{3}} \angle-30^{\circ}, \quad \mathbf{V}_{\text {bn }}=\frac{V}{\sqrt{3}} \angle-150^{\circ}, \quad \mathbf{V}_{\mathbf{c n}}=\frac{V}{\sqrt{3}} \angle 90^{\circ}$

The corresponding line currents are,

$\mathbf{I}_{\mathbf{s a}}=I \angle-210^{\circ}+\theta_{r}, \quad \mathbf{I}_{\mathbf{s b}}=I \angle 30^{\circ}+\theta_{r}, \quad \mathbf{I}_{\mathbf{s c}}=I \angle-90^{\circ}+\theta_{r}$

Power supplied by the inverter,

$$
\begin{aligned}
S_{i n v} & =V_{c b} I_{s c}^{*} \\
P_{i n v}+j Q_{i n v} & =V I\left\{-\cos \left(30^{\circ}+\theta_{r}\right)-j \sin \left(30^{\circ}+\theta_{r}\right)\right\}
\end{aligned}
$$

Real power drawn by the FEC is same as the real power delivered by the inverter. FEC current is given by,

$$
\begin{aligned}
V_{a b} I_{F E C} & =P_{i n v} \\
V I_{F E C} & =-V I \cos \left(30^{\circ}+\theta_{r}\right) \\
& \Rightarrow I_{F E C}=-I \cos \left(30^{\circ}+\theta_{r}\right)
\end{aligned}
$$

Grid current $I_{g}$ is,

$$
\begin{aligned}
& I_{g}=I_{s a}+I_{F E C} \\
& I_{g}=I \angle\left(-210^{\circ}+\theta_{r}\right)-I \cos \left(30^{\circ}+\theta_{r}\right) \\
& I_{g}=-I \cos \left(30^{\circ}-\theta_{r}\right)-j I \sin \left(30^{\circ}-\theta_{r}\right)-I \cos \left(30^{\circ}+\theta_{r}\right) \\
& I_{g}=-\sqrt{3} I \cos \left(\theta_{r}\right)-j I \sin \left(30^{\circ}-\theta_{r}\right)
\end{aligned}
$$

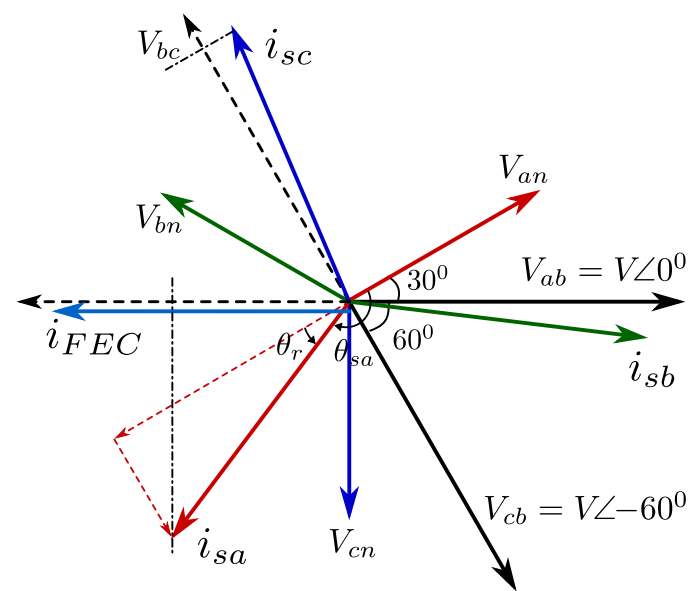

(a)

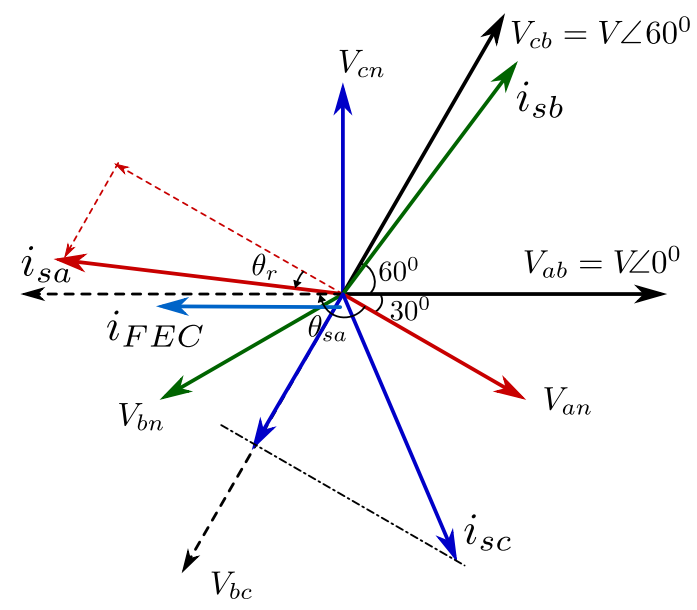

(b)

Fig. 4. Phasor diagram indicating ways to operate active phase converter based IG for single-phase grids. (a) $v_{c b}$ lags $v_{a b}$ (b) $v_{c b}$ leads $v_{a b}$.

Power drawn from the single-phase grid,

$$
\begin{aligned}
& P+j Q=V_{a b} I_{g}^{*} \\
& P+j Q=V I\left\{-\sqrt{3} \cos \left(\theta_{r}\right)+j \sin \left(30^{\circ}-\theta_{r}\right)\right\}
\end{aligned}
$$

As $\theta_{r}$ for the analysis of the IG is considered positive, it can be observed from (5) and (11), that the $v_{c b}$ leading $v_{a b}$ results in smaller $I_{F E C}$ magnitude. Similarly from (7) and (13), it can be seen for the same operating conditions, the grid power factor is better for the case when $v_{c b}$ leads $v_{a b}$. 


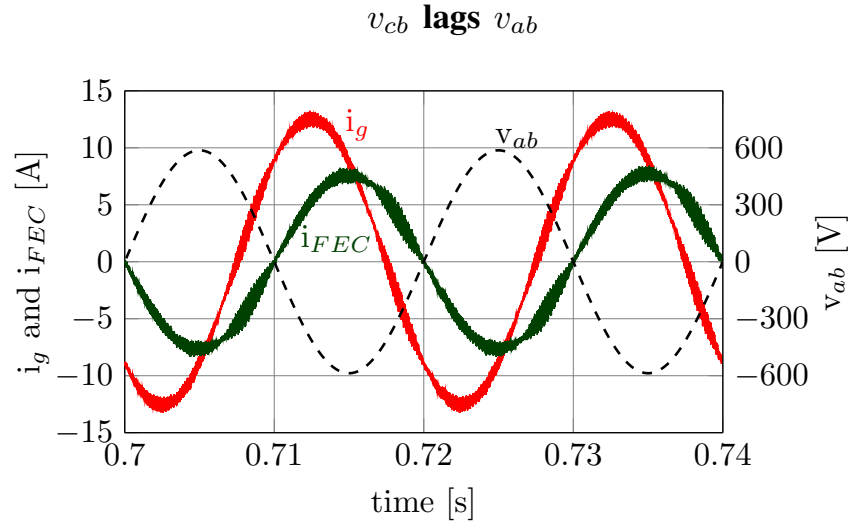

(a)

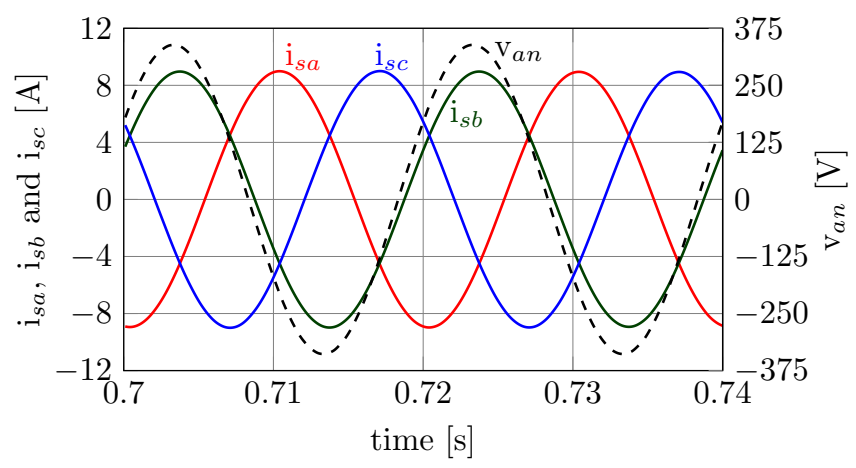

(c)

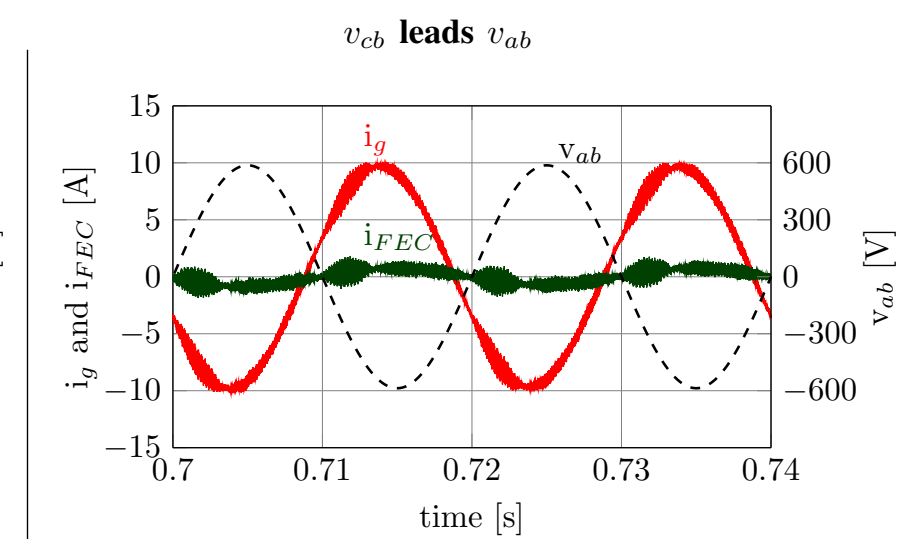

(b)

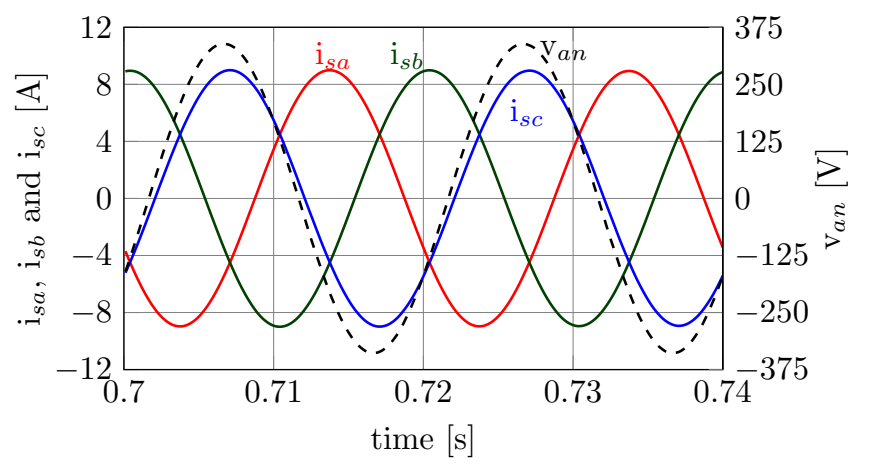

(d)

Fig. 5. Simulation results of the grid tied APC with the $3 \mathrm{~kW}$ IG indicating grid, FEC and IG currents for both the cases where $v_{c b}$ lags or leads $v_{a b}$. (a) and (b) Grid and FEC currents; (c) and (d) Induction generator currents.

TABLE I

COMPARISON OF ANALYTICAL AND SIMULATION RESULTS.

\begin{tabular}{|c|c|c|c|c|c|c|}
\hline \multirow{2}{*}{$\begin{array}{c}\text { Parameter (peak } \\
\text { fundamental) }\end{array}$} & \multicolumn{2}{|c|}{ (i) $v_{c b}$ lags $v_{a b}$} & \multicolumn{2}{c|}{ (ii) $v_{c b}$ leads $v_{a b}$} & \multicolumn{2}{c|}{ Reduction from (i) to (ii) } \\
\cline { 2 - 7 } & Analytical & Simulation & Analytical & Simulation & Analytical & Simulation \\
\hline$I_{F E C}(\mathrm{pk})$ & $8.65 \mathrm{~A}$ & $7.75 \mathrm{~A}$ & $1.3 \mathrm{~A}$ & $0.8 \mathrm{~A}$ & $85 \%$ & $90 \%$ \\
\hline$I_{g}(\mathrm{pk})$ & $13.58 \mathrm{~A}$ & $12.8 \mathrm{~A}$ & $10.55 \mathrm{~A}$ & $9.5 \mathrm{~A}$ & $23 \%$ & $26 \%$ \\
\hline Grid kVAR & 2.71 & 2.06 & 1.03 & 0.83 & $62 \%$ & $60 \%$ \\
\hline
\end{tabular}

\section{RESUlTS AND Discussion}

Simulation studies and experimental observations are performed to substantiate the theoritical framework that is presented in the analysis. A $3 \mathrm{~kW}$ induction machine operating as a generator whose parameters are tabulated in Table-III is employed in these studies. No reactive power compensation control is incorporated in the APC, to improve pf at grid.

\section{A. Simulation Results}

For the simulation studies, a load torque of $-20 \mathrm{Nm}$ applied, to take the machine into regenerating mode. From the steadystate IG currents and phase voltages presented in Fig. 5(c) and (d), $\theta_{r}$ defined in (1) is found to be $52^{\circ}$. Also, from Fig. 5(c) and $(\mathrm{d})$, it can be seen that the loading on the IG is same for both the cases, $v_{c b}$ lags $v_{a b}$ and $v_{c b}$ leads $v_{a b}$. Fig. 5(a) shows the case where the FEC and grid currents are significant, and considerable inductive reactive power is drawn from the grid. Whereas, Fig. 5(b) has reduced FEC and grid currents with an improved power factor at the grid. It can be observed from Fig. 5(c) and (d) that the generator three-phase currents are balanced when operating with the APC for both the cases where $v_{c b}$ lags or leads $v_{a b}$. The FEC and grid currents and corresponding kVAR at the grid are tabulated in Table-I. The theoretical and simulation results for both the cases where (a) $v_{c b}$ lags $v_{a b}$ and (ii) $v_{c b}$ leads $v_{a b}$ are in close agreement. It is found that the reduction $\mathrm{kVAR}$ at the grid by $60 \%$, FEC and grid currents by more than $80 \%$ and $20 \%$ respectively for the case (ii) over the case (i) as can be seen from the results of simulation and analysis tabulated in Table-I. The presented analysis and simulation results corroborate that the control approach where $v_{c b}$ leads $v_{a b}$ is preferred over the case where $v_{c b}$ leads $v_{a b}$, for the APC used in the IG applications.

\section{B. Experimental Results}

The application of APC for regeneration, using an IG is tested with two cases (i) $v_{c b}$ lags $v_{a b}$ (ii) $v_{c b}$ leads $v_{a b}$, as 
$v_{c b}$ lags $v_{a b}$

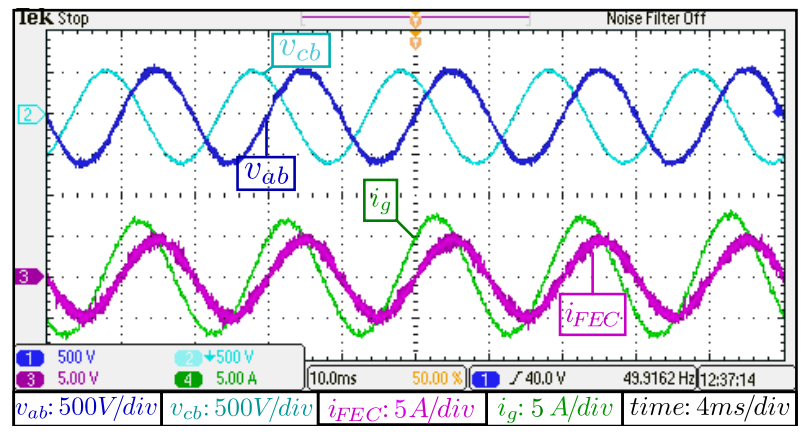

(a) $v_{c b}$ leads $v_{a b}$

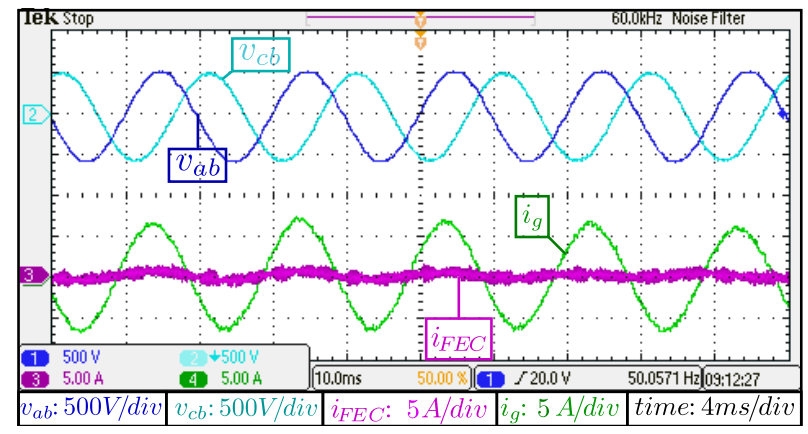

(b)

Fig. 6. Experimental results of the grid tied APC with the $3 \mathrm{~kW}$ IG rotating at $1560 \mathrm{rpm}(1.04 \mathrm{pu})$ speed and injecting $1.5 \mathrm{~kW}$ power for lag and lead control methods. (a) $v_{c b}$ lags $v_{a b}$. (b) $v_{c b}$ leads $v_{a b}$.

discussed in Sections-II and III. Fig. 8 shows the photograph of the laboratory prototype converter used as APC. The experimental results shown in Fig. 6 are taken to compare the effectiveness of appropriate reference voltage generation to reduce load on the converter and improve pf at the grid. Experimental results shown in Fig. 6(a) is for the cases where $v_{c b}$ lags $v_{a b}$ and Fig. 6(b) $v_{c b}$ leads $v_{a b}$. In both the cases, IG is injecting $50 \%$ of rated power to the single-phase grid while running at $1560 \mathrm{rpm}$ corresponding to a slip of $-0.04 \mathrm{pu}$.

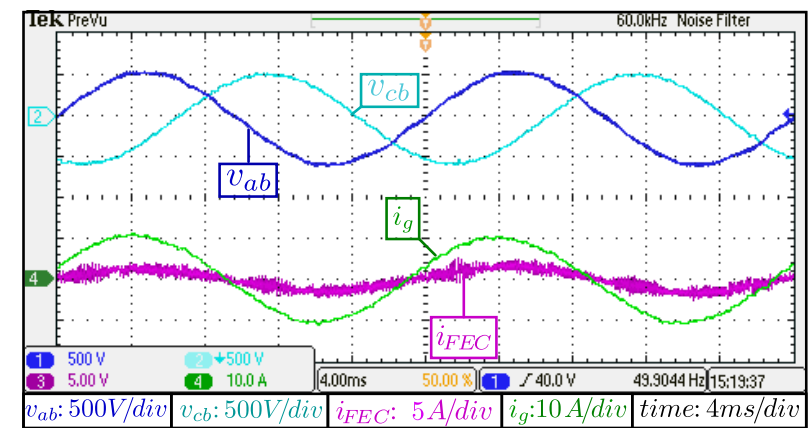

Fig. 7. Experimental results of the grid tied APC with the $3 \mathrm{~kW}$ IG rotating at $1600 \mathrm{rpm}(1.07 \mathrm{pu})$ speed and injecting $2.8 \mathrm{~kW}$ power with the APC control where $v_{c b}$ leads $v_{a b}$.

TABLE II

ANALYTICAL AND EXPERIMENTAL RESULTS OF GRID POWER FOR IG OPERATING AT $90 \%$ OF FULL LOAD.

\begin{tabular}{|c|c|c|c|c|}
\hline \multicolumn{2}{|c|}{ IG operating conditions } & \multicolumn{3}{|c|}{ Operating conditions of Grid } \\
\hline Parameter & Exp & Parameter & Theor & Exp \\
\hline$V_{\text {line }}$ & $394 \mathrm{~V}$ & $V_{g}$ & $394 \mathrm{~V}$ & $394 \mathrm{~V}$ \\
\hline$I_{\text {line }}(=\mathrm{I})$ & $6.1 \mathrm{~A}$ & $I_{g}$ (eq.12) & $7.32 \mathrm{~A}$ & $6.8 \mathrm{~A}$ \\
\hline$P_{I G}$ & $-2.75 \mathrm{~kW}$ & $P_{g}$ (eq.13) & $-2.78 \mathrm{~kW}$ & $-2.6 \mathrm{~kW}$ \\
\hline$Q_{I G}$ & $+3.13 \mathrm{kAR}$ & $Q_{g}$ (eq.13) & $-0.74 k \mathrm{VAR}$ & $-0.77 k \mathrm{VAR}$ \\
\hline$\theta_{r}$ & $48^{\circ}$ & Grid pf & $0.97(\uparrow)^{*}$ & $0.96(\uparrow)$ \\
\hline
\end{tabular}

${ }^{*}(\uparrow)$ indicates leading power factor

From the experimental results, it is evident that the FEC and grid currents for the case where $v_{c b}$ leads $v_{a b}$, is less compared to the case where $v_{c b}$ lags $v_{a b}$, for the same amount of real power, $1.5 \mathrm{~kW}$, supplied by the IG. A significant reduction in FEC current in Fig. 6(b), as compared to Fig. 6(a) indicates that the load on the inverter thereby the load on APC is less. This reduction in $i_{F E C}$ is observed for the different operating conditions of mechanical generation corresponding to $1.5 \mathrm{~kW}$ and $2.8 \mathrm{~kW}$ for generator in Fig. 6(b) and Fig. 7 respectively. The experimantal results in Fig. 7 shows for case $v_{c b}$ leads $v_{a b}$ and the IG is supplying a power of $2.8 \mathrm{~kW}$ resulting in a real power injection of $2.6 \mathrm{~kW}$ into the single-phase grid. The theoritical values corresponding to this case are compared with the experimental values and are found to be in close agreement.

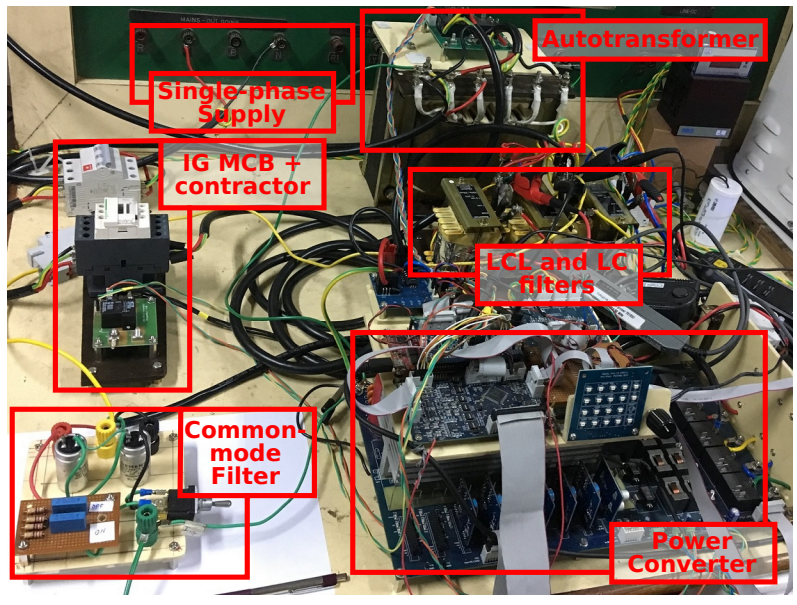

Fig. 8. Photograph of the experimental test set-up showing the APC.

\section{COnClusions}

In this work, a control approach for operation of an active phase converter (APC) in conjunction with an induction generator (IG) is proposed. From the qualitative analysis with the help of phasor diagrams, it is shown that the control in which the APC generated third phase $v_{c b}$ leading the grid voltage $v_{a b}$ is beneficial from the perspective of the converter loading when the conerter is operated with an induction generator. A quantitative analysis to obtain the grid and FEC current of the APC assisted IG is presented. Simulation results on a 
$3 \mathrm{~kW}$ IG substantiates the effectiveness of the APC control for injecting power from a three-phase IG to a single-phase grid. The experimental and simulation results are in close agreement with the analysis which validate the proposed control approach based on the theoritical framework. The proposed control approach is found to reduce kVAR at the grid thus resulting a reduction in the grid current with improved pf. The experimental results on a $3 \mathrm{~kW}$ induction generator at $90 \%$ of the rated load shows that a power factor of 0.96 is seen at the single-phase grid while injecting a $2.6 \mathrm{~kW}$ real power into the grid.

\section{APPENDIX}

Induction motor parameters used for simulation and experimental studies.

TABLE III

$3.0 \mathrm{KW}$ INDUCTION MACHINE PARAMETERS

\begin{tabular}{ccc}
\hline Parameter & Value & Per unit \\
\hline Rated voltage & $415 \mathrm{~V}(\Delta)$ & 1.0 \\
Stator resistance, $R_{s}$ & $1.56 \Omega$ & 0.047 \\
Rated current & $7.2 \mathrm{~A}$ & 1.0 \\
Stator leakage inductance, $L_{l s}$ & $18 \mathrm{mH}$ & 0.17 \\
Rated power & $3.0 \mathrm{~kW}$ & \\
Rotor resistance, $R_{r}$ & $2.62 \Omega$ & 0.079 \\
Number of poles & 4 & \\
Rotor leakage inductance, $L_{l r}$ & $18 \mathrm{mH}$ & 0.17 \\
Moment of inertia, $J$ & $0.1 \mathrm{~kg}-\mathrm{m}^{2}$ & \\
Magnetizing inductance, $L_{o}$ & $177 \mathrm{mH}$ & 1.67 \\
\hline
\end{tabular}

\section{REFERENCES}

[1] A. A. A. Aziz, R. A. Hamdy, A. S. Abdel-Khalik, and M. Y. A. Fattah, "Investigation of a three-phase self-excited induction generator feeding single-phase loads," in 11th IEEE Int. Conf. on Compatibility, Power Electronics and Power Engineering, April 2017, pp. 358-363.

[2] E. C. dos Santos Jr., C. B. Jacobina, E. R. C. da Silva, and N. Rocha, "Single-phase to three-phase power converters: State of the art," IEEE Trans. Power Electron., vol. 27, pp. 2437 - 2452, May 2012.

[3] O. Ojo, O. Omozusi, A. Ginart, and B. Gonoh, "The operation of a standalone, single-phase induction generator using a single-phase, pulse-width modulated inverter with a battery supply," IEEE Trans. Energy Conv., vol. 14, no. 3, pp. 526-531, Sept 1999.

[4] T. F. Chan and L. L. Lai, "Single-phase operation of a three-phase induction generator using a novel line current injection method," IEEE Transactions on Energy Conversion, vol. 20, no. 2, pp. 308-315, June 2005.

[5] J. B. Ekanayake, "Induction generators for small hydro schemes," Power Engineering Journal, vol. 16, no. 2, pp. 61-67, April 2002.

[6] Y. H. A. Rahim, A. I. Alolah, and R. I. Al-Mudaiheem, "Performance of single phase induction generators," IEEE Trans. Energy Conv., vol. 8, pp. 389-395, 1993.

[7] T. F. Chan and L. L. Lai, "A novel excitation scheme for a stand-alone three-phase induction generator supplying single-phase loads," IEEE Transactions on Energy Conversion, vol. 19, no. 1, pp. 136-143, March 2004.

[8] A. K. Adapa and V. John, "Active-phase converter for operation of threephase induction motors on single-phase grid," IEEE Trans. Ind. Appl., vol. 53, no. 6, pp. 5668-5675, Nov 2017.

[9] O. J. M. Smith, "Three-phase induction generator for single-phase line," IEEE Power Engineering Review, 1987.
[10] L. A. C. Lopes and R. G. Almeida, "Wind-driven self-excited induction generator with voltage and frequency regulated by a reduced-rating voltage source inverter," IEEE Transactions on Energy Conversion, vol. 21, no. 2, pp. 297-304, June 2006.

[11] C. . Chen, D. M. Divan, and D. W. Novotny, "A single phase to three phase power converter for motor drive applications," Oct 1992, pp. 639646 vol. 1.

[12] R. Teodorescu, F. Blaabjerg, M. Liserre, and P. C. Loh, "Proportionalresonant controllers and filters for grid-connected voltage-source converters," IEE Proc. - Ele. Power Appl., vol. 153, no. 5, pp. 750-762, September 2006.

[13] A. K. Adapa and V. John, "Virtual resistor based active damping of lc filter in standalone voltage source inverter," in IEEE Applied Power Electr. Conf. and Expo. (APEC), March 2018, pp. 1834-1840. 